\title{
Problem-Based Learning in Situ Applied to Students in the Assessment of Nursing Process
}

\author{
Margarita Acevedo-Peña1 ${ }^{(0)}$, Rosa María Ostiguín-Meléndez ${ }^{2}$, José Luis Cadena-Anguiano³, Mar- \\ cela Patricia Ibarra-Gonzalez ${ }^{3}$, Jesús Rigoberto Hernández-Hernández ${ }^{4}$ (1), \\ Rafael Villalobos-Molina ${ }^{5}$ (D), Diana Cecilia Tapia-Pancardo ${ }^{5 *}$ (])
}

\author{
${ }^{1}$ Facultad de Estudios Superiores Iztacala, Universidad Nacional Autónoma de México, Mexico City, Mexico \\ ${ }^{2}$ Escuela Nacional de Enfermería y Obstetricia, Universidad Nacional Autónoma de México, Mexico City, Mexico \\ ${ }^{3}$ Facultad de Estudios Superiores Iztacala, Universidad Nacional Autónoma de México, Mexico City, Mexico \\ ${ }^{4}$ Colegio de Posgrado de la Ciudad de México, city, Mexico \\ ${ }^{5}$ Unidad de Biomedicina, Facultad de Estudios Superiores Iztacala, Universidad Nacional Autónoma de México, Mexico City, \\ Mexico \\ Email: *dianacecitapia@hotmail.com
}

How to cite this paper: Acevedo-Peña, M., Ostiguín-Meléndez, R.M., Cadena-Anguiano, J.L., Ibarra-Gonzalez, M.P., HernándezHernández, J.R., Villalobos-Molina, R. and Tapia-Pancardo, D.C. (2021) Problem-Based Learning in Situ Applied to Students in the Assessment of Nursing Process. Open Journal of Nursing, 11, 378-389. https://doi.org/10.4236/ojn.2021.115033

Received: April 19, 2021

Accepted: May 23, 2021

Published: May 26, 2021

Copyright $\odot 2021$ by author(s) and Scientific Research Publishing Inc. This work is licensed under the Creative Commons Attribution International License (CC BY 4.0).

http://creativecommons.org/licenses/by/4.0/

\begin{abstract}
Background: Nursing is considered a science in the making that recognizes the nursing process (NP) as the scientific and methodological tool to provide care. The NP is composed of five stages of which the assessment is the first and fundamental to identify the health problems of the people. This research aimed to evaluate a pedagogical didactic strategy that is based on situated constructivism, the Based-Problem Learning (BPL), in order to improve significant learning. Methods: Quantitative research with an explanatory scope, was transversal, and it was applied to 30 students of the first year of the nursing career at the Faculty of Higher Studies Iztacala, National Autonomous University of Mexico. The sample was chosen considering the inclusion criteria. Data were collected using a Likert-type instrument validated in a previous investigation. Results: The average value obtained from the Likert scale to evaluate the intervention was 103.4, the highest score was 135 and the lowest was 83 , which reflects that it was evaluated as good and particularly good. The grade given to the teacher as an agent of the ZPD, was between agree and totally agree, the highest percentages scored at $93 \%$, since it provoked challenge in their thinking, and favored interaction among classmates. Conclusions: The application of the in situ teaching strategy, BPL favored significant learning of the assessment stage, the students were able to carry out the assessment in the hospital, the experience contributed to generate significant learning when students face real scenarios, which showed the effectiveness of the method.
\end{abstract}




\section{Keywords}

Learning Method, Nursing Process, Assessment

\section{Introduction}

Nursing process (NP) is an own method of nurse professionals, that explains and describes how to apply the scientific method to healthcare practice. By using this method nurse professionals provide rational, dynamic, and conscious decisions care, also logics to solve problems, priorities definition, and decisions taken to get better ways for health care. The NP originated from the theoretical basis proposed by Florence Nigthingale in the XIX century, it integrates nursing knowledge with epistemological elements such as person, surroundings, health and care, nursing philosophies, models and theories and empirical indicators used in the different steps of nursing process [1]-[7].

Due to its importance and significance NP has been studied from different views, like its teaching and application is a complex process to apply in clinical scenarios [8] [9] [10] [11] [12], where diverse situations occur that impair NP's objectives. Then nursing educational institutions search for the best teaching method [6] [7] [11] [13] [14]; however, no specific teaching method for NP assessment has been studied, even though it is a cornerstone of the process [1] [2] [3] [4] [5].

It was considered that in the teaching-learning process of assessing the main figure is the student, and the teacher acts as a facilitator [12] [15], and it was based on psychological, pedagogical, and philosophical theories of Vygotsky, Díaz Barriga and Sartre, respectively.

It is unquestionably that nurse professionals rely on Vygotsky's theories, they are trained into a social surrounding and share among peers, and guided by other professionals involved in significant activities who apply concepts like zone of proximal development (ZPD) to learn, such as student and teacher situation in a joint action toward defined goals, where the teacher acts a resource available to the student that helps to reach better learning than that self-acquired [16] [17] [18].

Vygotsky's theory focuses on social interaction that surrounds the individual, which leads to knowledge and essential skills for success in a particular culture. It does not consider the person as an independent explorer making decisive discoveries on his own, but instead sees the person in cognitive development as an activity mediated by society. ZPD is the process in which an expert, when instructing a novice in a situation of learning, responds in a contingent way to the behavior of the latter, so that little by little you know the problem better, with freedom of learning based on the next zone of development [16] [17].

Renkl and $\mathrm{Ku} \& \mathrm{Ha}$ referred that all knowledge as a product of learning or thinking-cognition actions, could be defined as being situated in the context of a 
determined situation and results from a person's learning activity by interacting with others, in a sense of social practices promoted from a determined community [19] [20].

The situated cognition paradigm is one of the most representative and promising current tendencies of sociocultural theory and activity; it does assume diverse shapes and names, directly linked to concepts such as situated learning, legitimate peripheral participation, cognitive apprenticeship or craft learning. The situated teaching is an in situ learning method, considered as a strategy based in socio-constructivist that resumes aspects of Vygotsky's theory, regarding that learning is learnt in persons' social contexts and their interactions, it resumes the cognitive constructivism paradigm because is a product of learning or thinking-cognition acts, from the social settings [13] [16] [17] [18].

In situ learning is based on the contemporary model of situated cognition, i.e., apprenticeship model, which seeks to develop skills and knowledge of the nursing profession, as well as their participation to solve social problems or the pertaining community. It emphasizes the usefulness or functionality of the learned subject, as well as learning in real settings [16] [17] [18].

Nursing teaching-learning is a training process higher than $70 \%$ learnt in real settings, right with persons requiring care. First there is contact with persons or simulators to approach that reality, and then they integrate it in hospital units of the three attention levels, such that there is a continuous social and cognitive interaction with teachers and peers which improve personal knowledge construction, and particularly the joint construction with peers and those subjects of care. This process is guided, supervised and feedback by a nurse teacher, with an approach and application of Vygotsky's DPZ, elements to chose the strategy which explains the pedagogic and psychological trends supporting it [16] [19] [20] [21] [22]. The aim of the study was to evaluate a didactic-pedagogic strategy supported in a situated constructivism principle, i.e., an in situ learning method, BPL that will contribute to improving significant learning during the assessment of NP, for a better quality in nursing students learning at FESI-UNAM.

\section{Methods}

An exploratory study was conducted to approach reality and obtain information, recognize, locate and define problems that allow refine the method [23]. Quantitative research with an explanatory and transversal scope. Explanatory research accounts reality or its comprehension through scientific theories, elucidate which factor facts-associated determine the observed response, and the accuracy of dependent and independent variables relationships [23]. The current study explained how significant learning occurred in the assessment of nursing step applying the situated teaching, PBL. The study was transversal with one measurement to seek students' learning, and the significant learning progress in estimating NP. The epistemological frame for this study was revised from general and specific aspects, considering the axiological aspect as important and relevant for 
nursing students and teachers in the situated teaching, the PBL as a support to improve significant learning for the assessment of NP. The ontological aspects were related to social surroundings, the nature of investigation taken in account that nurse student acquired significant learning, which resulted in care quality for professional activity. The epistemological aspects pertained to whom and what, and were considered to explain that nurse students were studied regarding situated teaching, PBL as a support of significant learning in the assessment of NP. The theoretical basis were Vygostky's sociocultural theory [16] [17], Diaz-Barriga's situated constructivism theory [18] [19], and Sartre's existentialism [12] [15] [24].

\subsection{Inclusion Criteria}

First year nursing students from Facultad de Estudios Superiores Iztacala, Universidad Nacional Autónoma de México. The educational strategy was carried out in first-year students, aiming for an impact on their learning, and it is in this period that they first meet the nursing assessment, and that it would be reinforced throughout the professional training.

\subsection{Universe Sample}

From a universe of 300 nursing students of a public university, a simple of 30 subjects that met inclusion criteria were invited to participate. The sample included 26 women and 4 men.

\subsection{Information Gathering}

A questionnaire of 27 items was the instrument used to evaluate the strategy, with a Likert type scale (Strongly disagree, Disagree, Neither agree nor disagree, Agree, Strongly agree), based in the in situ method Problem-Based Learning PBL, as support and improvement of thinking abilities [18] [25], considering the following items (Table 1):

Professor as development zone agent (ZPD) (9 items);

Student's performance ( 7 items);

Course organization (11 items).

\subsection{Procedure}

In situ method PBL for teaching and learning during assessment of NP consisted in the following: students were in direct contact with assigned persons, doing physical exploration of human body systems, which is part of the assessment of NP. The strategy was conducted in the classroom, in nurse's laboratory and in the hospital, having the instruments and materials for each session. The process lasted 80 hours along 8 weeks; in the first week the theoretical support of the

Table 1. Instrument.

Item Strongly disagree Disagree Neither agree nor disagree Agree Strongly agree


assessment step (vital signs, somatometry, perimetry) was revised. Throughout the second and third weeks the clinical history, the physical exploration, behavior, and general aspects were evaluated; during the fourth week the nursing diagnosis, NANDA, planning, execution and evaluation [9]. In the fifth week the physical exploration of nervous, tegumentary, musculoskeletal, and cardiovascular systems; during the sixth week the physical exploration of respiratory, digestive, genitourinary, and urinary systems were evaluated. In the seventh week the physical exploration of an external person, and in the eighth week the physical exploration of a person in the hospital were done. The instrument was applied at the end of programming.

\subsection{Data Analysis}

Analysis and processing of the study data were done with the statistical package SPSS, version 20. Results of the instrument evaluating teacher's intervention as a ZPD, student's performance and course organization, considered the highest score as 135 and the lowest score as 27 (Table 2).

\subsection{Ethics and Legal Aspects}

Ethics and legal aspects were based on the principles of the Declaration of Helsinki, point 6 "The right to safeguard the integrity of persons must always be respected. All needed precautions must be adopted to respect intimacy of persons, reduce to a minimum the impact of the study on their physical, mental and personality". An informed consent letter was signed by each informer according to the Nüremberg code and local law [25] [26] [27].

\section{Results}

The educational strategy was carried out in several sessions, which required continuous monitoring and counseling by the researcher to maintain control of the implementation, to do that a limited number of participants were chosen. On the other hand, the exploratory research reflected that the rest of the teachers did not know the method in situ, which prevented the implementation of the strategy on their part. The sociodemographic characteristics of the participants are presented in (Table 3 ).

The Likert's scale obtained average for intervention was 103.4, being 135 the highest value and 83 the lowest value, meaning that it was evaluated as good and

Table 2. Instrument's score.

\begin{tabular}{ccc}
\hline Score & Evaluation \\
\hline $0-27$ & Deficient \\
$28-61$ & Regular \\
$62-95$ & Good \\
$95-135$ & Very good \\
\hline
\end{tabular}


Table 3. Sociodemographic characteristics of the participants.

\begin{tabular}{cc}
\hline Age & \\
20 - 21 years & $89 \%$ \\
19 - 20 years & $10 \%$ \\
Over 21 years & $1 \%$ \\
Sex & \\
Female & $87 \%$ \\
Male & $13 \%$ \\
Work experience & without work experience \\
Civil estatus & \\
Single & $99 \%$ \\
Married & $1 \%$ \\
Student & \\
Regular & $90 \%$ \\
Irregular & $10 \%$ \\
\hline
\end{tabular}

very good. The grade given to the teacher as a ZPD agent was between agree and strongly agree, the highest scored $93 \%$ since it provoked challenge in their thinking and favored interaction between classmates (Figure 1, Table 4).

\section{Discussion}

There are a number of definitions for the nursing process; however, in the current study Acosta-Salazar's et al. definition was used [28], in which NP is a "systematic and organized method to manage integral and progressive nursing care, centered in identification and treating the responses to health needs" [28]. Nursing process observed the scientific method steps, which supports the theoretical structure that led to knowledge and acted as a professional guidance. It is a model that underlies the professional nursing care, to engage the scientific knowledge and research, the professional work and it must be present at the beginning of the nursing professional training, accompanied by teachers along the program to reach the objectives, which coincided with the highest score for teachers as agents of ZDP, since they promoted a challenge in students' thinking and favored their interaction. This showed the importance of teachers encouraging innovative pedagogic strategies in the teaching-learning process, to search for significant learning such as PBL. According to Ku \& Ha, and Morales-Bueno, PBL allows nursing students to integer theory and practice en every context [20] [29]. Those authors raised that PBL involves constructivist ideas such as learn how to learn, collaborative work in small teams, and solving real problems; it provides the base to exchange ideas, team work and the chance to synergize communication and management abilities. It also allow the cultural and social interactions among students; while the complete evaluation of the situated teaching, 
Table 4. Opinion of the students in the learning of the: "NP assessment stage".

\begin{tabular}{cccc}
\hline Item & $\begin{array}{l}\text { Strongly } \\
\text { disagree }\end{array}$ & Disagree $\begin{array}{l}\text { Neither agree } \\
\text { nor disagree }\end{array}$ Agree Strongly agree
\end{tabular}

\section{Teacher as Zone of Proximal Development Agent}

1.-The professor's teaching skills favored a meaningful learning process

$30 \%$

2.-The professor taught through interaction, constant feedback and by sharing their knowledge

3.-The professor stimulated classmate interaction

4.-The professor stimulated the development of communication and interaction skills between classmates and tested people

5.-The professor maintained group dynamics during the demonstration of nursing assessment

6.-The professor stimulated the analysis of cases and critical thinking

7.-The professor stimulated the performance of procedures and enforced them by repetition

8.-The professor integrated the assessment stage in the nursing clinical history

9.-The professor incited challenges in the thinking process

\section{Student's Performance}

10.-Work dynamics incited the need to use reflective and analytical thinking in me

11.-The way of working encouraged me to work collaboratively

12.-My performance, enthusiasm and commitment were factors that positively influenced the learning of the assessment stage of the nursing care process

13.-The assessment stage allowed me to identify people's health problems and needs

14.-I was able to identify my cognitive and procedural learning needs while making the nursing assessment

15.-The situated teaching strategy in situ method allowed me to identify the learning needs that I must strengthen

16.-The teaching method led me to think about the consequences of my professional nursing actions

\section{Course Organization}

17.-At the beginning of the session, there was an adequate schedule

18.-The development of the session was carried out with the sequence required to for the nursing assessment

19.-The final integration practices allowed you to evaluate your learning

20.-The different scenarios chosen for learning the assessment stage facilitated it

21.-The times destined for each session allowed the achievement of what was planned

22.-The session objectives were met

23.-Working with this methodology allowed me to generate new ideas to deal with the classes 


\section{Continued}

24.-I opened up to the idea that this method can be useful for the implementation of the nursing process

25.-I would recommend this learning method to other colleagues

$3 \%$

$\begin{array}{ll}27 \% & 70 \% \\ 10 \% & 90 \% \\ 33 \% & 67 \%\end{array}$

26.-Learning the assessment stage allowed me to give importance to the nursing process as a nurse

27.-The transition between steps of the process was logical and natural

Source: data obtained after applying the Likert scale to a nurse group in FESI-UNAM.

Total score

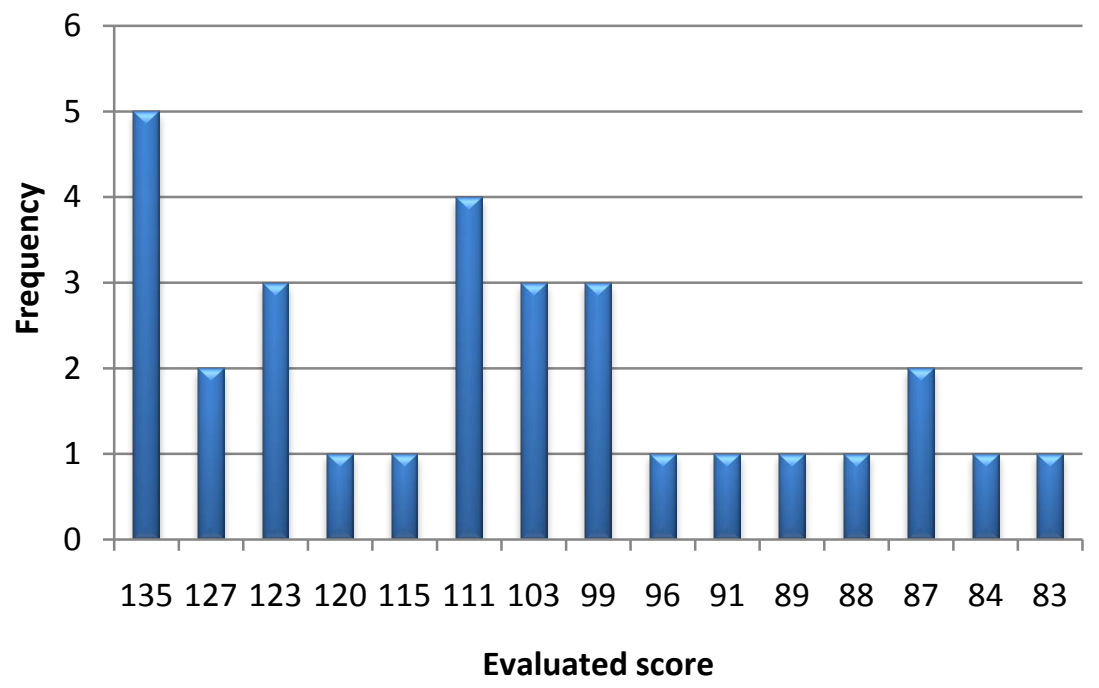

Figure 1. Total score to evaluate the intervention. Source: data obtained after applying the Likert scale to a nurse group in FESI-UNAM.

the method of in situ learning PBL applied in the strategy showed that $97 \%$ and 93\% agreed or strongly agreed, translated to the efficacy of the method to support significant learning during NP assessment.

According to Andrade Cepeda NP features highlight that it is an open and flexible method, since it satisfied individual needs, family needs and community needs, it is a cyclic and dynamic process because each step is interrelated, it is centered in the user and satisfies particular needs. It does have a concrete and programmed purpose, and it is interactive so that assumes a relationship between nurse and cared person [5]. By seeking the purpose to give individualized and specific care with a theoretical support, it is used as a basic structure to attend any given health situation along the life of the person; which agrees with the finding that $80 \%$ students mentioned that PBL led them to think about their professional acting as nurses and $77 \%$ referred that work dynamics generated the need to use analytic and reflexive thinking, supported in significant learning. Hung and Lin determined that PBL had a strong effect in knowledge acquisition and integration in a quasi-experimental study, and it potentiated motivation and significant learning in nursing students [30]. 
Among the goals of NP it is highlighted that it stimulated observation ability, professional growth, abilities development, active interaction between nurse and patient. It prevented omissions and repetitions, and promoted a better professional communication, which is coincident with the finding of $73 \%$ students mentioned that NP assessment allowed to identify problems and health needs of persons. According to Carpenito there is a growing interest in the diagnostic phase of NP, since nursing care efficacy depended of the ability to identify patient's diagnostics or potential problems; at the same time, the efficacy in identifying problems, intellectual abilities like critical and creative thinking, problem solving and decisions taken, depended of the full evaluation and interpretation of the obtained data in this step [31] [32].

The proposal seeks integration of to know, to do, and to act in nursing students in the assessment of nursing process step, to contribute for significant learning in students [33].

The results obtained in the research may suggest the use of the PBL method to improve the learning of nursing assessment; however, it is necessary to continue doing research in this regard, given the disciplinary importance of the subject in the professional life of the nurse.

\section{Conclusions}

Applying the in situ teaching strategy PBL favored significant learning during the assessment step, since students significantly assessed human body systems with a hospitalized patient; the experience contributed to significant learning because students face real scenarios, based on Vygotsky's, Díaz-Barriga's and Sartre's theories.

\section{Limitations of the Study}

Teachers did not know the situated teaching in situ PBL method.

\section{Acknowledgements}

Supported by PAPIME 300920, DGAPA, UNAM.

\section{Authors' Contributions}

The authors collaborated for the research. MAP, JRHH advised the design of the protocol and drafted the manuscript, DCTP and RVM processed the manuscript for publication. JLCA, RMOM, MPIG, collected and analyzed the data. All the authors read and approved the final manuscript.

\section{Conflicts of Interest}

The authors declare no conflicts of interest regarding the publication of this paper.

\section{References}

[1] Ead, H. (2019) Application of the Nursing Process in a Complex Health Care Envi- 
ronment.

https://www.canadian-nurse.com/en/articles/issues/2019/september-2019/applicati on-of-the-nursing-process-in-a-complex-health-care-environment\#: :text=The $\% 20$ steps\%20of\%20the\%20nursing,addressed\%20(Morris\%2C\%202006

[2] Watkins, T., Whisman, L. and Booker, P. (2015) Nursing Assessment of Continuous Vital Sign Surveillance to Improve Patient Safety on the Medical/Surgical Unit. Journal of Clinical Nursing, 25, 278-281. https://doi.org/10.1111/jocn.13102

[3] Toney-Butler, T.J. and Thayer, J.M. (2020) Nursing Process. StatPearls Publishing, Treasure Island.

[4] Raso, A., Ligozzi, L., Garrino, L. and Dimonte, V. (2019) Nursing Profession and Nurses' Contribution to Nursing Education as Seen through Students' Eyes: A Qualitative Study. Nursing Forum, 54, 414-424. https://doi.org/10.1111/nuf.12349

[5] Andrade-Cepeda, R.M. and Chávez-Alonso, M.R. (2004) Manual of Nursing Care Process. Editorial Universitaria Potosina, México. (In Spanish)

[6] Hernández-Ledesma, Y., Fernández-Camargo, I., Henríquez-Trujillo, D. and Lorenzo-Nieves, Y. (2018) Nursing Care Process: Strategies for Teaching-Learning. Revista Iberoamericana de Educacion e investigacion en enfermeria, 8, 46-53. (In Spanish)

[7] Hektor Dunphy, L.M. (2015) Florence Nightingale's Legacy of Caring and It's Applications. In: Smith, M.C. and Parker, M.E., Eds., Nursing Theories and Nursing Practice, 4th Edition, Davis Company, Boston, 37-54.

[8] Bird, M., Tolan, J. and Carter, N. (2019) Baccalaureate Nursing Students' Perceptions of Learning in Mentored and Simulated Research Practica. Journal of Nursing Education, 58, 290-293. https://doi.org/10.3928/01484834-20190422-07

[9] Campos, C., Jaimovich, S., Wigodski, J. and Aedo, V. (2017) Knowledge and Clinical Use of Nursing Methodology (NANDA, NIC, NOC) in Nurses Working in Chile. Revista Iberoamericana de Educacion e investigacion en enfermeria, 7, 33-42. (In Spanish)

[10] Karimi, H. (2011) Applying Nursing Process Education in Workshop Framework. Procedia-Social and Behavioral Sciences, 29, 561-566. (In Spanish) https://doi.org/10.1016/j.sbspro.2011.11.276

[11] Jara-Sanabria, F. and Lizano-Perez, A. (2017) Application of the Nursing Process, a Study from the Students' Experience. Journal of Nursing \& Patient Care, 2, 561-566. https://doi.org/10.4172/2573-4571.1000110

[12] Semachew, A. (2018) Implementation of Nursing Process in Clinical Settings: The Case of Three Governmental Hospitals in Ethiopia. BMC Research Notes, 11, Article No. 173. https://doi.org/10.1186/s13104-018-3275-Z

[13] Lambie, A., Schwend, K. and Scholl, A. (2015) Utilization of the Nursing Process to Foster Clinical Reasoning during a Simulation Experience. SAGE Open, 5, 1-6. https://doi.org/10.1177\%2F2158244015617516

[14] Fernández-Sánchez, H., Ortiz-Vargas, I. and Enríquez-Hernández, C.B. (2018) Community Nursing Process: A Healthy Lifestyle. Nursing \& Care Open Access Journal, 5, 145-147. https://doi.org/10.15406/ncoaj.2018.05.00137

[15] Troncoso, G.D., Pérez, V.C., Vaccarezza, G.G., Aguilar, A.C. and Muñoz, N.N. (2017) The Influence of Pedagogic and Discipline Training on the Teaching Quality of University Professors. Revista médica de Chile, 145, 610-618. (In Spanish) https://doi.org/10.4067/S0034-98872017000500008

[16] García, C.A. and Vivas, J. (2007) Exploring the Zone of Proximal Development: A 
Comparison between Two Techniques. PSIC-Revista de Psicologia da Vetor Editora, 8, 151-158. (In Spanish)

[17] Bodrova, E. (1997) Key Concepts of Vygotsky's Theory of Learning and Development. Journal of Early Childhood Teacher Education, 18, 16-22.

https://doi.org/10.1080/1090102970180205

[18] Díaz-Barriga, A.F. and Hernández-Rojas, G. (2010) Estrategias docentes para un aprendizaje significativo: Una interpretación constructivista. Mac Graw Hill, México. (In Spanish)

[19] Renkl, A. (2001) Situated Learning: Out of School and in the Classroom. In: Smelser, N.J. and Baltes, P.B., Eds., International Encyclopedia of the Social \& Behavioral Sciences, Pergamon, Oxford, 14133-14137. https://doi.org/10.1016/B0-08-043076-7/02442-6

[20] Ku, T.K. and Ha, M. (2016) The Application of Problem Based Learning in Undergraduate Nursing Education: A Strategy for Curriculum Reform. Journal of Bios ciences and Medicines, 4, 52-59. https://doi.org/10.4236/jbm.2016.46008

[21] Hernández-Rojas, G. (1997) Módulo Fundamentos del Desarrollo de la Tecnología Educativa (Bases Psicopedagógicas). Unidad 1. Paradigmas de la Psicología Educativa. Coord.: Frida Díaz Barriga Arceo. Latin American Institute of Educational Communication-Latin America Education Organization. (In Spanish)

[22] Thomas, A., Menon, A., Boruff, J., Rodriguez, A.M. and Ahmed. S. (2014) Applications of Social Constructivist Learning Theories in Knowledge Translation for Healthcare Professionals: A Scoping Review. Implementation Science, 9, Article No. 54. https://doi.org/10.1186/1748-5908-9-54

[23] Mousavinasab, E.S, Kalhori, S.R.N., Zarifsanaiey, N., Rakhshan, M. and Ghazisaeedi, M. (2020) Nursing Process Education: A Review of Methods and Characteristics. Nurse Education in Practice, 48, Article ID: 102886. https://doi.org/10.1016/j.nepr.2020.102886

[24] Sartre, J., Macomber, C., Cohen-Solal, A. and Elkaïm-Sartre, A. (2007) Existentialism Is a Humanism. In: Kulka, J. Ed., Existentialism Is a Humanism, Yale University Press, New Haven, 17-72. https://doi.org/10.2307/j.ctv15vwkgx.5

[25] Mukherjee, SP. (2020) A Guide to Research Methodology: An Overview of Research Problems, Tasks and Methods. CRC Press, New York.

https://doi.org/10.1201/9780429289095

[26] Resnik, D.B. (2020) What Is Ethics in Research \& Why Is It Important? https://www.niehs.nih.gov/research/resources/bioethics/whatis/index.cfm

[27] Miles, M., Huberman, A., Saldaña, J. and Chapter E. (2014) Ethical Issues in Analysis. In: Miles, M. and Huberman, A., Eds., Qualytative Data Analysis: An Expanded Sourcebook, 3rd Edition, Sage Publications, Thousand Oaks, 107-255.

[28] Acosta-Salazar, D., Lapeira-Panneflex, P. and Ramos-De La Cruz, E. (2016) Nursing Care Community Health. Duazary, 13, 105-110.

https://doi.org/10.21676/2389783X.1715

[29] Morales-Bueno, P. (2018) Problem-Based Learning (PBL) and Critical Thinking Skills-A Binding Relationship? Revista Electrónica Interuniversitaria de Formación del Profesorado, 21, 91-108. (In Spanish) https://doi.org/10.6018/reifop.21.2.323371

[30] Hung, C.H. and Ling, C.Y. (2015) Using Concept Mapping to Evaluate Knowledge Structure in Problem-Based Learning. BMC Medical Education, 15, Article No. 212. https://doi.org/10.1186/s12909-015-0496-x 
[31] Carpenito-Moyet, L.J. (2007) The Nursing Process and Concept Mapping. In: Carpenito-Moyet, L.J., Eds., Understanding the Nursing Process. Concept Mapping and Care Planning for Students, Lippincott Williams \& Wilkins, Philadelphia, 34-41.

[32] Ballantyne, H. (2016) Developing Nursing Care Plans. Nursing Standard, 30, 51-60. https://doi.org/10.7748/ns.30.26.51.s48

[33] Organisation for Economic Co-Operation and Development (OECD) (2016) Insights from the TALIS-PISA Link Data: Teaching Strategies for Instructional Quality. 